\title{
Editorial
}

\section{Fenómenos sociales extremos: Las personas en situación de calle}

La situación de las personas que habitan la calle no constituye un fenómeno extremo por el solo hecho de carecer de una vivienda, el carácter de extremo viene dado también por la frustrada experiencia de conexión con la familia y la comunidad que las personas en situación de calle enfrentan y las consecuencias que este fracaso de interacción reporta. Hemos querido abordar en este número 75 de la revista Trabajo Social el fenómeno de las personas en situación de calle, como una contribución a la visibilización de una situación de vida extrema que sólo hace unos pocos años las políticas sociales chilenas han afrontado, y como una forma de poner en cuestión supuestos y prácticas e invitar a nuestros lectores a repensar las definiciones, estereotipos y clasificaciones con los que interrogamos e intervenimos la realidad de las personas en situación de calle.

Este número recopila una selección de las conferencias centrales del seminario Personas en Situación de Calle organizado por el Programa de Política Pública de la Universidad Católica, permitiendo dar cuenta del movimiento generado tras el primer catastro de personas en situación de calle realizado en Chile por el gobierno y organizaciones no gubernamentales el año 2005. Además presenta investigaciones desarrolladas por jóvenes profesionales chilenos que tuvieron la posibilidad de vincularse al mundo de las personas en situación de calle y reflexionar sobre esa experiencia de soledad e incomunicación que a pesar de parecer homogénea es, en realidad, muy diversa en su interior, afectando de manera distinta a mujeres y hombres adultos, niños, niñas y adolescentes. Esto también lo comprueban las dos investigaciones finales de este número, realizadas por académicos de Trabajo Social en Estados Unidos, país donde el fenómeno de las personas en situación de calle se vincula al cierre de las instituciones psiquiátricas. Ambos estudios muestran la heterogeneidad del fenómeno al abordarlo en conjunto con otras problemáticas que suelen ser concomitantes: VIH, género, consumo de drogas y enfermedades mentales.

Las conclusiones de estos artículos coinciden en la necesidad de generar soluciones reales que permitan integrar a las personas en situación de calle a la sociedad y promover su independencia, medidas que sólo pueden ser alcanzadas al intervenir desde visiones interdisciplinarias que superen alternativas medicalizantes, o puramente centradas en la solución habitacional. Las personas en situación de calle viven cada día la experiencia extrema de la soledad y de aislamiento, de allí que el rol de comunidad y la contribución psicosocial sea fundamental para rehabilitar el aspecto más quebrado en este fenómeno: el vínculo social.

\section{Margarita Quezada Venegas Directora \\ Escuela de Trabajo Social Pontificia Universidad Católica de Chile}

